\title{
Is Patellectomy Compatible with an Army Career?
}

\author{
Lt Col C A Pailthorpe \\ FRCS(Ed), RAMC \\ Senior Registrar in Orthopaedic Surgery
}

\author{
Maj S Milner \\ FRCS, RAMC
}

Senior Registrar in General Surgery

Royal Army Medical College, Millbank, London SW1 4RJ

\author{
Mrs M M Sims \\ BSc \\ Statistician \\ MOD Medical Statistics Branch
}

SUMMARY: The aim of this study was to assess the impact of patellectomy on the service career of soldiers. Information on 184 individuals on whom patellectomy was performed between 1981 and 1986, was retrieved from computer records. The criterion for success of the operation was the recovery to a fully fit category.

Fifty three patients $(29 \%)$ regained full fitness. The outcome of patellectomies performed for chondromalacia patellae and osteoarthritis appears to be worse than that for patellar fractures.

\section{Introduction}

Patellectomy is an operation that has vacillated in and out of fashion over the years. It was performed by Putz(1) in 1860 for habitual dislocation of the patella and at the turn of the century patellectomy was used in the management of chronic arthritis, osteomyelitis of the patella, chondromalacia patellae and fractures.

There has been a divergence of opinion in the literature on the role of patellectomy in the management of such conditions and especially in chondromalacia patellae. In 1978 Bentley(2) strongly supported patellectomy in the management of chondromalacia patellae. He compared the results of patellectomy with patellar tendon transfer, shaving of the patella and cartilage excision and drilling of the subchondral bone. He had good results, $82 \%$ of the 34 patients who had primary patellectomies achieved satisfactory results and $62 \%$ of cases who had patellectomy after a previous operation had a satisfactory result. This compared to only $25 \%$ satisfactory results for patella shaving and overall $60 \%$ satisfactory results for patella tendon transfer.

A leading editorial on chondromalcia patellae in the British Medical Journal in 1981(3) stated: 'the knee tolerates repeated surgical insults badly and there may be something to be said for moving straight from conservative treatment to excision of the patella, but only after careful, critical and prolonged observation of the patient'.

Knee pain is a common complaint in Army personnel. Wilson(4) in 1983 recorded prospectively the incidence of patellofemoral pain in a Junior Infantry Unit and found that $18 \%$ presented with symptoms. In the late
1970 s and early 1980 s, chondromalacia patellae was the common diagnosis for pain related to the patella. Th\& anterior knee pain syndrome had not been full 8 evaluated. Many operations for the treatment of chondromalacia patellae were attempted and patelf $\underset{5}{0}$. ectomy was often the final outcome. As the years passeg a general impression developed that patellectomy in the. management of chondromalacia patellae was not successful operation in terms of recovery to full fitness.

The aim of this study was to review, statistically, the outcome of Service personnel who underwent patellectomy between January 1981 and December 1986 and to answer the question "is patellectomy compatible with an Army career?"

No attempt has been made to review these patients clinically.

\section{Methods}

Information on in-patient admissions over 48 hours, of Service personnel is held on computer at the Medical Statistics Department, Stanmore, Middlesex. The medical fitness categories of all Service personnel are held on the central Army computerised Pay and Records system at Worthy Down. Information was retrieved in May 1987 and confirmed in February 1989 and included: 1. Principal diagnosis

2. Date of operation

3. Personal details

4. Numbers still serving

5. Numbers leaving the Service for non-medical reasons 6. Numbers leaving on medical discharge

7. Medical fitness categories

8. Exit codes giving reason for leaving. 
The principal diagnosis is as defined by the Manual of the International Classification of Diseases. Three broad groups were defined:- chondromalcia patellae, osteoarthritis and patellar fractures. There were no cases where patellectomy was performed for recurrent dislocation of the patella.

Most of the authors who have reviewed the results of patellectomy base their assessment on a variety of criteria such as: recurrence of pain, giving way, range of movement, effusions, extensor lag, quadriceps strength tests etc. An example of such an assessment was described by Bentley in 1970(5). For the purposes of this study we defined two outcome groups, those that regained a fully fit category and those that did not.

Fitness categories in the Army are based upon the PULHHEEMS classification as laid down in the PULHHEEMS Administrative Pamphlet. Fully fit is classified as forward everywhere - FE which implies employable at full combatant duties in any area in any part of the world. If the category was not FE then, for the purposes of the study, they were classified as unfit.

The FE category demands a fitness requirement as laid down in the Army Training Directive consisting of a run wearing boots, the first 1.5 miles run as a squad in 15 minutes and the second 1.5 miles run in the individual best time within a limit set by age and sex (eg $<29$ years -11.5 minutes for men).

It is a reasonable assumption that if following a patellectomy a patient can pass this fitness test, then the operation can be considered as successful.

The medical categories of personnel who left for nonmedical reasons were those which were attained at the time of leaving the Service. Personnel who were medically discharged from the Service due to their disability are obviously included in the unfit category.

The distribution of cases between the three diagnostic groups was examined over the study period and associations between diagnostic category and service outcome were assessed using the chi-squared test. Average age at operation and the time between operation and discharge were compared between diagnostic groups and outcome groups using analysis of variance (ANOVA) techniques and the distributionfree Kruskal-Wallis test. Homogeneity of variance was assessed by the Bartlett and Cochran $\mathrm{C}$ tests and normality of the data by examination of standardised coefficients of skewness and kurtosis. Significance levels, $p$, of $<0.05$ were considered to indicate statistically significant results.

\section{Results}

One hundred and eighty four patellectomies were performed on 184 individuals between 1981 and 1986. The number of operations performed each year declined over the study period with only 11 performed in 1986 (Table 1).

As the distribution of cases between the three diagnostic groups was broadly similar in each year of the
Table 1

Numbers of operations performed each year by Service outcome at March 1990

\begin{tabular}{lrrrrrrr}
\hline & 81 & 82 & 83 & 84 & 85 & 86 & Total \\
$\begin{array}{l}\text { Non-medical } \\
\text { Exit }\end{array}$ & 23 & 28 & 12 & 11 & 6 & 1 & 81 \\
Medical & & & & & & & \\
Discharge & 13 & 15 & 10 & 12 & 4 & 3 & 57 \\
Serving & 8 & 9 & 7 & 8 & 7 & 7 & 46 \\
Total & 44 & 52 & 29 & 31 & 17 & 11 & 184 \\
\hline
\end{tabular}

study period, it is reasonable to make comparisons between these categories in terms of fitness status and service outcome and also duration from operation to exit for those no longer serving. Thus the study clearly shows that whilst more than half $(54 \%)$ of the patellar fracture group regained full fitness, the large majority of the chondromalacia patellae and osteoarthritis groups remained unfit (Table 2). The chi-squared test of $p=$ 0.003 is highly significant. There was however, no significant difference between the diagnostic groups in terms of service outcome (Table 3 , chi-squared test $\mathrm{p}=0.5$ ).

A 2-way analysis of variance of the age at operation by diagnosis and service outcome (Table 4) highlights significant differences between the outcome groups with the mean age being significantly lower in the medicap discharge group. Those that received a medicat discharge left sooner after the operation than those who left for non-medical reasons (Table 5). The reasons for leaving the Service were identified from the exit codes as laid down in Queen's Regulations. A wide variety of reasons was found with no particular one dominating (Table 6), however, if one adds the premature voluntary release group with those that left after giving appropriate notice, it suggests that half left due to dissatisfaction with their potential prospects in the Army.

The patellar fracture group included 14 acute fractures and 10 cases in which patellectomy was performed late. There were 10 females in the study: one (who had chondromalacia patellae) was medically discharged and one achieved full fitness. All 4 in the serving group had chondromalacia patellae and in the exist group 4 had chondromalacia patellae and one osteoarthritis.

\section{Discussion}

Inevitably some assumptions have been made during this study. The disease index code is a potential source of error, not in relation to the patellar fracture group but in the distinction between chondromalacia patellae and osteoarthritis. Below the age of 30 years, the difference between the two is probably irrelevant and perhaps both 
Table 2

Association between principal diagnosis and fitness status attained subsequent to patellectomy

\begin{tabular}{lcrr}
\hline & \multicolumn{2}{c}{ Number of cases } \\
& \multicolumn{1}{c}{ Fit } & Unfit & Total \\
\hline Chondromalacia & & & \\
patellae & $15(12 \%)$ & $109(88 \%)$ & 124 \\
Osteoarthritis & $12(33 \%)$ & $24(67 \%)$ & 36 \\
Patellar Fracture & $13(54 \%)$ & $11(46 \%)$ & 24 \\
Total & $40(22 \%)$ & $144(78 \%)$ & 184 \\
\hline
\end{tabular}

Table 3

Association between principal diagnosis and outcome group

$\begin{array}{ccc}\text { Non- } & \text { Number of cases } \\ \begin{array}{c}\text { Nedical } \\ \text { Exit }\end{array} & \begin{array}{c}\text { Medical } \\ \text { Discharge }\end{array} & \text { Serving }\end{array}$

Chondromalacia

$\begin{array}{lllll}\text { patellae } & 57(46 \%) & 41(33 \%) & 26(21 \%) & 124\end{array}$

$\begin{array}{lllll}\text { Osteoarthritis } & 18(50 \%) & 8(22 \%) & 10(28 \%) & 36\end{array}$

$\begin{array}{lllll}\text { Patellar Fracture } \quad 6(25 \%) & 8(33 \%) & 10(42 \%) & 24\end{array}$

$\begin{array}{lllll}\text { Total } & 81(44 \%) & 57(31 \%) & 46(25 \%) & 184\end{array}$

No significant association $p=0.13$, chi-squared test.

Table 4

Age at operation by principal diagnosis and outcome group

Mean (standard deviation) - Years

Non-

medical Medical Serving Total

Exit Discharge

\begin{tabular}{lcccc}
\hline Chondromalacia & 28.0 & 23.8 & 29.0 & 26.8 \\
patellae & $(6.2)$ & $(4.4)$ & $(5.6)$ & $(5.9)$ \\
Osteoarthritis & 30.7 & 28.9 & 23.4 & 28.3 \\
& $(8.1)$ & $(7.6)$ & $(3.9)$ & $(7.5)$ \\
Patellar & 28.3 & 21.9 & 26.7 & 25.5 \\
Fractures & $(8.7)$ & $(3.1)$ & $(6.4)$ & $(6.5)$ \\
Total & 28.6 & 24.3 & 27.3 & 26.9 \\
& $(6.8)$ & $(5.1)$ & $(5.8)$ & $(6.3)$ \\
\hline
\end{tabular}

Significant differences in age at operation exist between outcome groups ( $p<0.001$ for 2-way analysis of variance and Kruskal-Wallis test), but not between diagnostic groups $(\mathrm{p}=0.4$ for both tests).
Table 5

Time from operation to leaving the Service by principal diagnosis and reason for exit

\begin{tabular}{|c|c|c|c|}
\hline & \multicolumn{3}{|c|}{ Mean (standard deviation) - Years } \\
\hline & $\begin{array}{c}\text { Non- } \\
\text { medical } \\
\text { Exit }\end{array}$ & $\begin{array}{l}\text { Medical } \\
\text { Discharge }\end{array}$ & $\begin{array}{l}\text { Total } \\
\text { - all } \\
\text { Exits }\end{array}$ \\
\hline $\begin{array}{l}\text { Chondromalacia } \\
\text { patellae }\end{array}$ & $2.7(2.0)$ & $1.6(1.5)$ & $2.3(1.8)$ \\
\hline Osteoarthritis & $3.3(2.4)$ & $2.2(1.8)$ & $3.0(2.2)$ \\
\hline $\begin{array}{l}\text { Patellar } \\
\text { Fractures }\end{array}$ & $2.5(2.2)$ & $0.9(1.3)$ & $1.6(1.8)$ \\
\hline Total & $2.8(2.1)$ & $1.6(1.5)$ & $2.3(1.9)$ \\
\hline
\end{tabular}

Highly significant differences in time to exit exist between non-medical exits $(p<0.001)$ and, to a lesser extent, between diagnostic groups $(\mathrm{p}=0.05)$, KruskalWallis test.

Table 6

Breakdown of reasons for leaving the Service among non-medical exits

\begin{tabular}{ccc}
\hline Code & Category & Number \\
\hline
\end{tabular}

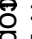

$\begin{array}{rl}10 & \text { Vol retired } \\ 201 & 3,6,9 \text { year opt (A res) } \\ 211 & \text { Reg 4 of ATSR 1967 } \\ 212 & \text { Completed engagement } \\ 224 & \text { Purchase not to res } \\ 225 & \text { Purchase to a res } \\ 251 & \text { Dismissed by cm } \\ 253 & \text { Misconduct } \\ 259 & \text { Retn undesirable } \\ 262 & \text { Not required further } \\ 264 & \text { Serv nolonger required } \\ 304 & \text { Compassionate } \\ 305 & \text { Reg 11(5) ATSR 1967 } \\ 306 & \text { Free after 22+ years } \\ 307 & \text { Free after 16+ years } \\ 310 & \text { Free on marriage }\end{array}$

1
14
11
22
3
6
1
1
2
11
2
1
2
1
1
2
81


grants should be considered together.

Another source of error is in the exit group, in that some of the personnel may have achieved a good result after they left the Service. However as nearly half of the group left of their own accord, it suggests that their recovery was not full and they left because their Army career had been jeopardized.

It has become clear that the anterior knee pain syndrome is a distinct entity and the number of true cases of chondromalacia patellae with definitive articular cartilage changes is small. It is likely that many of those cases labelled chondromalacia patellae in the early 1980s, were in fact, sufferent from anterior knee pain and patellectomy would now be considered as inappropriate treatment. The review article on patellectomy by Kelly and Insall(6) in 1986 clearly highlights this point. Though they considered their results as fair they conclude: "the patella should not be removed indiscriminately for the treatment of anterior knee pain since alternative management can usually be found".

This study demonstrates that patellectomy in the management of patellar related pain is not compatible with an Army career. In cases of patellar fracture the outlook is more promising.

\section{REFERENCES}

1. COHN B N E. Total and partial patellectomy. An experimental study. Surg Gynaecol Obstet 1944; 79: 526.

2. BENTLEY $G$. The surgical management of chondromalacia patellae. J Bone Joint Surg 1978; 60-B: 74-87.

3. Editorial. BrMJ 1981; 282: 1014.

4. WILSON K Cet al. A study of patellofemoral pain in a Junior Infantry Training Unit. J R Army Med Corps 1983; 129: 82-87.

5. Bentley G. Chondromalacia patellae. J Bone Joint Surg 1970; 52-A: 221-232.

6. Kelly M A, Insall J N. Patellectomy. Orthop Clin North Am 1986; 17: 289-293.

\section{JOURNALS/PUBLICATIONS RECEIVED}

The following Journals/Publications have been received and are available in the Royal Army Medical College Library.

\section{JOURNALS}

Annales Chirugiae et Gynaecologiae; Annales Medicinae Militare Belgicae; Annals of Medicine; Archives of Surgery; Army Wives Journal; Australian \& New Zealand Journal of Surgery.

Boletin de la Oficina Sanitaria Panamericana; British Medical Journal + Index Jan-Jun 90; Bulletin of the Academy of Military Medical Sciences, Beijing, China; Bulletin of the Pan American Health Organization; Bulletin of the World Health Organization \& Supp to Vol 67 1989, Infant Feeding - The Physiological Basis.

Central African Journal of Medicine. Giornale Di Medicina Militare. Indian Journal of Medical Research, The; Irish Medical Journal.

Journal of the Egyptian Medical Association; Journal of the Royal Naval Medical Services + 75th Anniversary re-issue of Vol 1 No: 1 1915; Journal of the Royal Society of Health; Journal of the Royal Society of Medicine + Annual Report 1989-90 \& Calendar 1990-91 \& Index Vol 821989 \& Supp; Journal of Traffic Medicine; Journal of the US Army Medical Dept, The.

Lancet, The; Medicine Tropicale; Medicina Militar; Military Medicine; Military Review.

National Defense Medical Journal, Tokyo. Quarterly Journal of Medicine.
Revista de Medicina Militara, Romania; Revista de Sanidid de la Defensa Nacional, Chile, 1986-89; Revista de Sanidad Militar; Revista do Instituto de Medicina Tropical de Sao Paulo; Revista Portuguese de Medicina Militar; Revue Internationale de Services de Sante des Forces Armees; Royal Army Pay Corps Journal; Royal Engineers Journal, The.

Scottish Medical Journal; South African Medical Journal; Tropical Diseases Bulletin. Vojnosanitetski Pregled (Military - Medical and Pharmaceutical Review of the Yugoslav People's Army).

Wehrmedizinische Monatsschrift; World Health Forum.

\section{PUBLICATIONS}

Accidents and Emergency Nursing - 2nd Edn - M Walsh, Heinemann Nursing, 1990; Aids and its Metaphors - Susan Sontag, Penguin, 1990.

Craftsman, The. Effectiveness and Efficiency - A L Cochrane, British Medical Journal, 1989, NAAFI News; Not a Proper Doctor-D Sinclair, British Medical Journal, 1989.

Penguin Nursing Revisions Notes - Care for the Elderly - P A Hollingham, Penguin, 1990. SSAFA News, 1990.

Tanky Challenor - SAS and the MET - H Challenor \& A Draper, Leo Cooper, 1990. Year Book of Infectious Disease - Ed S M Wolff, Year Book Medical Pubns, 1990. 